International Journal of Current Advanced Research

ISSN: O: 2319-6475, ISSN: P: 2319 - 6505, Impact Factor: SJIF: 5.995

Available Online at www.journalijcar.org

Volume 6; Issue 3; March 2017; Page No. 2429-2431

DOI: http://dx.doi.org/10.24327/ijcar.2017.2431.0021

Case Report

\title{
A RARE VARIANT INNERVATION OF ADDUCTOR POLLICIS MUSCLE FROM MEDIAN NERVE IN AN ADULT CADAVER IN MIDDLE EAST: A CASE REPORT
}

\author{
Shweta Chaudhary ${ }^{1^{*}}$ and Rishi Kumar Bharti ${ }^{2}$ \\ ${ }^{1}$ Department of Anatomy, College of Medicine, King Khalid University, Abha, \\ Kingdom of Saudi Arabia, PO Box 418, Asir 614312 \\ ${ }^{2}$ Department of Community Medicine, College of Medicine, King Khalid University
}

\section{A R T I C L E I N F O}

\section{Article History:}

Received $10^{\text {th }}$ December, 2016

Received in revised form $7^{\text {th }}$ January, 2017

Accepted $11^{\text {th }}$ February, 2017

Published online $28^{\text {th }}$ March, 2017

\section{Kye Words:}

Adductor pollicis muscle; Variant; Innervation; Median nerve; Thumb

\begin{abstract}
A B S T R A C T
Few sporadic reports have been found in past and some of them described this as an etiological factor for incomplete nerve decompression or erroneous results during electrophysiological studies. Here we describe a rare case of adductor pollicis muscle in hand which was supplied from branch arising from lateral ramus of median nerve. In past, such variation in innervation of adductor pollicis brevis has never been reported in this region. Presence may be attributed to rerouting of nerve fibers at various levels. Particularly in light of the increasing number of nerve conduction studies, knowledge of normal and variant anatomic features has become more important than in the past.. Knowledge about variant innervation pattern would thus aid in correct explanation of results during motor testing of hypothenar and thenar muscles and while interpreting variant symptomatology in carpal tunnel syndrome and muscle contractures. Prior academic knowledge in nerve supply of muscles are extremely important and awareness would thus help to prevent iatrogenic injuries and better prognosis in cases of nerve decompression procedures, muscle flap transplant and various graft surgeries.
\end{abstract}

Copyright $₫ 2017$ Shweta Chaudhary and Rishi Kumar Bharti. This is an open access article distributed under the Creative Commons Attribution License, which permits unrestricted use, distribution, and reproduction in any medium, provided the original work is properly cited.

\section{INTRODUCTION}

Highly specialized and intricate movements, characteristic of human hand is attributed to several intrinsic muscles and are considered as responsible for its prehensile function. Magnitude of evolution of intrinsic muscles of hand is considered as an indirect index of civilization of human race. This may be attributed to the fact that flexor and adductor muscle contributes significantly to the grasping ability of human hand. Hence during phylogeny great revolution has occurred a in evolution of human hand. This is hypothesized due to a great neuromuscular coordination and representation of larger functional area for hand in motor and sensory cortex of the cerebrum. Out of all the muscles of hand, the adductor muscles especially of thumb have a significantly greater role to play in the intricate movements of thumb. The adductor muscles contributed to the precise movements which are required during evolution. Hands are used by many arboreal frogs to manipulate food and to bring food to the mouth using complex rotations at the wrist. Ability to perform these complex movements is interpreted as an significant factor for the specialization of the forelimbs for locomotion. [1]

\section{*Corresponding author: Shweta Chaudhary}

Department of Anatomy, College of Medicine, King Khalid University, Abha, Kingdom of Saudi Arabia, PO Box 418, Asir 614312
Grays et al in 1997 described that adduction of the thumb towards the digits such that the palmar surfaces of the thumb and digit touch each other is required for a precision grip. Precision grip is thought to be used during locomotion and in the manipulation of some food items. [2]

Adductor pollicis (ADP) is described as having oblique and transverse heads. The oblique head arises from the capitate bone and the bases of the second and third metacarpal bones. Most of the fibers unites with the tendon of the transverse head, and is inserts to the ulnar side of the base of the proximal phalanx of the thumb. Deep branch of ulnar nerve supplies ADP along with the first palmar interosseous and flexor pollicis brevis.[3] The long flexor tendons provide the power of the grip, the short intrinsic muscles of the hand are responsible for adjusting the movement and carrying out the finer skilled movements of the digits and specialized motion.[4]

\section{Case Report}

The purpose of present commentary is to report a case of rare innervation of adductor pollicis muscle from median nerve which was encountered during routine cadaveric dissection of 49 yrold male cadaver who died of myocardial infarction. The rare finding was seen on left side with nerve to ADP 
originating from lateral ramus of median nerve (figure 1 and 2).

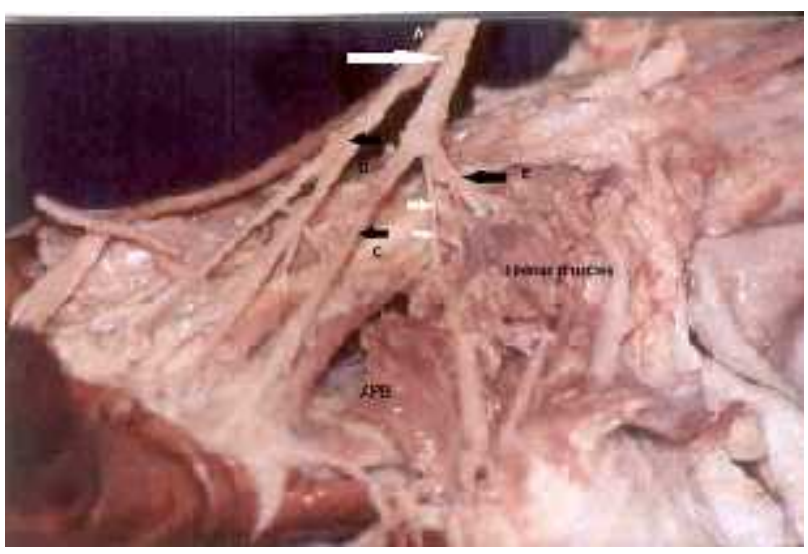

Figure 1 Showing: Median Nerve (A); Recurrent Muscular Branch (B); Proper Digital Nerve To Index Finger (C); Common Digital Nerve To Index, Middle And Ring Finger (D); Adductor Pollicis (APBorADP)

Small White Arrow Shows: Nerve to Adductor Pollicis (APB orADP)

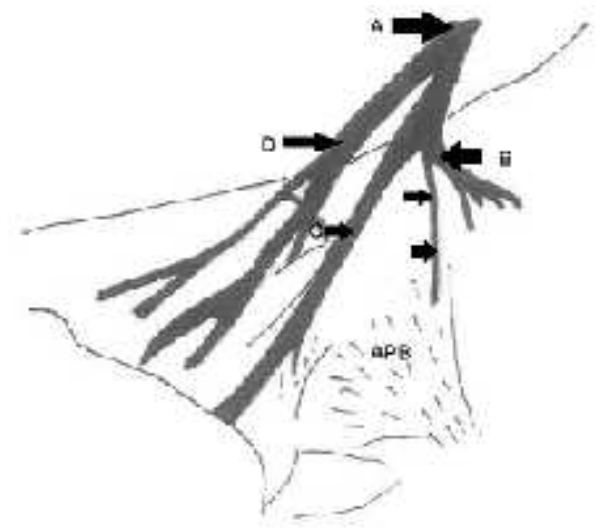

Figure 2 Diagramatic Representation of Figure 2 Showing: Median Nerve (A); Recurrent Muscular Branch (B); Proper Digital Nerve To Index Finger (C); Common Digital Nerve To Index, Middle And Ring Finger (D); Adductor Pollicis (APB orADP)

Small Black Arrow Shows: Nerve To Adductor Pollicis (APB orADP)

Strikingly, no communication between median and ulnar nerve was seen in arm or forearm and hand. The nerve supplied the muscle from its superficial aspect. The nerve supplied both its deep and transverse heads. Median nerve entered hand deep to flexor retinaculum and divided into lateral and medial ramus. Lateral ramus divided into recurrent muscular branch to opponens pollicis, abductor pollicis brevis and flexor pollicis brevis and proper digital nerve to thumb and radial side of index finger. Medial ramus divided into common digital nerves for index and middle finger and lateral side of ring finger. In addition to this it supplied first and second lumbrical muscles in hand through proper digital nerves to index and middle finger.

\section{DISCUSSION}

The normal hand function is the balance between the extrinsic and intrinsic muscles. Much of the importance of the hand is dependent on the action of the thumb. Functionally, the thumb is considered as half of the hand, which acts in the opposite direction to the fingers in order to grasp any object. The thumb mobility is under the control of long and short muscles. [4]
A surgeon is exposed to topographical anatomy of the neural structures during surgical procedures of hand, and awareness of variations may be of immense clinical help. Prior academic knowledge seems necessary for better understanding and correct interpretation of clinical neurophysiological studies. [5]

When the radius and ulna chondrify, by stage 17, the branched tips of the radial, median and ulnar nerves have migrated to the distal hand plate. (3) Significant variations in nerve patterns may result from altered signaling between mesenchymal cells and neuronal growth factors. [6]

Raviprassana et al in 2104 described adductor pollicis was supplied by median nerve in $11.7 \%$ cases. $7.8 \%$ were on right side $3.9 \%$ cases were reported on left side.[7]

Mizia et al in 2011, observed variations in 60 hands $.71 .7 \%$ Lanz type I variant - branching of thenar branch of median nerve was reported, Level of origin of thenar branch was extraligamentous in $50 \%$, sub-ligamentous in $20 \%$ and transligamentous in $1.67 \%$ cases. [8]

Vashistha et al in 2011 reported normal branching pattern of median nerve in $30 \%$ cases. Left side hands were reported in $57 \%$ cases as having more variations as compared to right hands. Single thenar branch of median nerve was found in $66 \%$ cases. [9]

Elsabeh et al in 2005 reported the adductor pollicis was supplied by deep branch of ulnar nervein $93.33 \%$ cases. In $6.67 \%$ cases adductor pollicis was supplied in addition by a branch from median nerve. [4]

Homma and Sakai reported that innervation by median nerve was specially seen for lateral fibers of the muscle. Schultz and Kaplan reported that adductor pollicis muscle was supplied by the median nerve in all cases. $[10,11]$

Mohammed et al described that adductor pollicis did not receive pure median innervation in anycase. It received the ulnar nerve in $90.5 \%$ of the cases and mixed innervation was seen in $9.5 \%$ cases. $66.7 \%$ of cases, mixed innervation was shown in opponens pollicis. Twig from deep branch of the ulnar nerve supplied the deep stratum of the flexor pollicis brevis after giving its supply to the adductor pollicis muscle while the twig from the median nerve supplies the superficial stratum of flexor pollicis brevis was described. [12]

King in 1951 reported a case in which all the intrinsic muscles of the hand were innervated by the median nerve. [13]

Rowntree in 1949 found that all the thenar muscles were innervated by the ulnar nerve in $2 \%$ and just by the median nerve in another $2 \%$. [14]

Median and ulnar nerves anastomosis is considered as the most common form of anomalous innervation, causing variations in the nerve supply of the intrinsic muscles of the hand. $[15,16]$

Ferrari and Gilbert described a "danger zone", defined as an area that extends from the middle ofthe hypothenar eminence limited distally by the transverse carpal crease on the palmar region and laterally by a longitudinal fold between the thenar and hypothenar eminence. They described it as an area in which there is increased possibility of iatrogenic lesions in the approach to the carpal tunnel.[17] 
Raised pressure in the carpal tunnel may result in median nerve compression and altered nerve perfusion may lead to discomfort and paraesthesia in the hand of affected side which may require surgical procedure for decompression. [18]

Significant variation has been recognized in the nerve supply of the intrinsic muscles of the hand muscles which may have clinical implications. Knowledge of anatomical variations on the part of the surgical team is extremely important to avoid iatrogenic injuries and improve the prognosis of median nerve decompression and various graft surgeries. The clinical relevance of these variations emerges in the nerve injured patient with apparent function distal to the level of injury. It becomes considerably important while investigating lesions of nerves whichare distributed to the hand in order to establish the diagnosis and to plan adequate treatment. Both during the initial evaluation of cases of injury and for planning reconstructive surgery of such patients, the possibility of anatomical variant patterns must be considered.

\section{CONCLUSION}

Variations in innervation of adductor muscle have drawn lot of attention due to its clinical implications. At present, every practicing clinician and surgeon must have in-depth knowledge of such variations for better understanding of structures in operative field. Pre-operative diagnosis of such variant innervation would aid for better prognosis in various nerve decompression surgeries and flap transplants. Electrophysiological study, performed in the presence of anatomical variations, could lead to erroneous interpretation of results. A thorough understanding of the anatomical variations will enable the use of electro diagnostic studies in conjunction with clinical examination for accurate conclusions and further diagnosis and treatment of patients with neuromuscular disorders. Further research about their presence especially in cases of median -ulnar anastomosis emphasizing rerouting of nerve fibers can provide new insights and reasons for its presence.

\section{Acknowledgements}

We are grateful to all our faculty members for their kind support and encouragement at every step. We also thank our college administration for incredible support and wishes.

\section{References}

1. Manzano AS, Abdala V, Herrel A. Morphology and Function of the Forelimb in Arboreal Frogs: Specializations for Grasping Ability?. J. Anat, 2008; 213(3):296-307.

2. Gray L, O'Reilly JC, Nishikawa KC. Evolution of forelimb movement patterns for prey manipulation in anurans. J Exp Zool,1997; 277, 417-424

3. Standring S, Ellis H, Healy JC, Johnson D, Williams A, Collins P, et al. Fore arm and Hand. In: Gray's Anatomy - The anatomical basis of clinical practice. 40th ed. Edinburgh: Churchill Livingstone, 2005; 895-
4. Elsabeh S., Mokhtar Z, Hassan A, Biram D. Anatomical study of the arterial and nerve supply of the thenar muscles. I- Nerve. New York, Oxford, Philadelphia, St Louis, Sydney, Toronto, 2005; 889933.

5. Das S, Paul S. Anomalous branching pattern of lateral cord of brachial plexus. Int J Morphol 2005; 23(4):282292.

6. Sanes H. D., Reh T. A., Harris W. A. Development of the nervous system. New York. Academic Press; 2000: 189-197

7. Raviprasanna KH, Poornima GC, Dakshayani K. R Study of branching pattern of median nerve at carpal tunnel and its importance in surgical anatomy. IJBR, 2014); 5 (9):566-570

8. Mizia E, Klimek-Piotrowska W, Walocha J, Rutowski $\mathrm{R}$, Wojtala R. The median nerve in the carpal tunnel. Folia Morphol, 2011; 70 (1):41-6.

9. Vashishtha K. Variations of median nerve in carpal tunnel and its distribution in hand. J Anat Soc India 2011; 60(2):193-8.

10. Homma T, Sakai T. Thenar and Hypothenar muscles and their innervation by the ulnar and median nerves in the human hand. Acta Anatomica, 1992; 145:44-9.

11. Suhultz R, Kaplan EB. Nerve supply to the muscles and skin of the hand. In: Morton-Kaplan's Functional and Surgical Anatomy of the Hand. 1984:222-43.

12. Mohammed O, SalmanA, JaffarFB. Hamdan. Motor innervation of the short muscles of the thumb: anatomic and clinical Implications, Iraqi J Med Sci, 2005; 4 (2): 119-124

13. King RB. Anomalous innervation of the hand muscles. Journal of Neurosurgery, 1951:8, 528-529.

14. RowntreeT. Anomalous innervation of the hand muscles. Journal of Bone and Joint Surgery, 1949; 31(B), 505-510.

15. Kimura J, Murphy MJ, Varda DJ. Electrophysiolgical study of anomalous innervationsof intrinsic hand muscles. Arch Neurol. 1976;33(12):842-4.

16. Mannerfelt L. Studies on the hand in ulnar nerve paralysis. A clinical-experimentalinvestigation in normal and anomalous innervation. Acta Orthop Scand.1996;Suppl 87( 2):1 19.

17. Ferrari GP, Gilbert A. The superficial anastomosis on the palm of the handbetween the ulnar and median nerves. J Hand Surg Br. 1991;16(5):511-4.

18. Demircay E, Civelek E, Cansever T, Kabatas S, Yilmaz C. Anatomic variations of the median nerve in the carpal tunnel: A brief review of the literature. Turkish Neurosurgery 2011; 21(3):388-9.

\section{How to cite this article:}

Shweta Chaudhary and Rishi Kumar Bharti (2017) 'A Rare Variant Innervation Of Adductor Pollicis Muscle From Median Nerve In An Adult Cadaver In middle East: A Case Report', International Journal of Current Advanced Research, 06(03), pp. 2429-2431. 